\title{
An International Housing Market in the British Isles: Evidence from Business and Medium-Term Cycles using a Friedman Test
}

\begin{abstract}
It has been averred that there is an international market in housing (inter alia Adams \& Füss, 2010; Helbling \& Terrones, 2003; Pomogajko \& Voigtländer, 2012). Although some authors examine the business cycle range, the mechanism by which this comes about is more likely to reflect financial market integration and evidence for this should be found in the medium-term cycle range. As a case study, there is an analysis of three associated 'regional' housing markets and their price movements. Northern Ireland's economy is distinct but should be linked to the rest of the UK by common policy shocks, and to Eire through a mutual border. Using a Friedman test, it is found that even this small cluster is not integrated.

It is asserted that a housing cycle has both a financial and a business component. As Drehmann et al. (2012) argue, cycles in the medium-term range are significant in housing. A dual component approach highlights the relevance of cyclical interaction for both revealing integration and the need to intervene to moderate cyclical reinforcement for crisis-avoidance.

Post-1995, Dublin and London are found to be more integrated than before, which is consistent with international city integration thesis of Holly et al. (2011). Lastly, a simple test for cyclical asymmetry indicates that there is highness in the UK financial cycle.
\end{abstract}




\section{An International Housing Market in the British Isles: Evidence from Business and Medium-Term Cycles using a Friedman Test}

\section{Introduction}

Housing market areas comprise real estate sites that are influenced by the same underlying (latent) forces, so that a cluster of sites that form a market area should be characterised by a high order of price comovement (Clark \& Coggin, 2009; DiPasquale \& Wheaton, 1996). Markets defined by common or convergent trends increasingly find London is distinct (inter alia Gray, 2018b; Montagnoli \& Nagayasu, 2015; Tsai, 2015) yet its reach covers most of the south of England (De Goei, et al., 2010). Common trends are routinely revealed by error correction models. However, 'structural breaks' due to bubbles (Gregoriou, 2014), make results subject to date-selection issues and to the number of breaks identified. Markets defined by one common or a collection of convergent cycles (inter alia Crone, 2005; De Haan et al. 2008; Pomogajko \& Voigtländer, 2012) assessed by cluster analysis, correlation and principal components analysis, encounter fluctuating relationships that, if asynchronous, can be underestimated. A less restrictive 'similarity in shape' (Aghabozorgi et al., 2015) criterion could reveal more integration than other approaches.

It has been averred that there is an international market in housing (inter alia Adams \& Füss, 2010; Helbling \& Terrones, 2003; Pomogajko \& Voigtländer, 2012). The mechanisms by which this comes about are more likely to reflect financial markets than the flows of labour or trade. Drehmann et al. (2012) (DBT) reveal a financial cycle best characterised by the comovement of medium-term cycles in credit and property prices.

There is an analysis of three associated 'regional' housing markets and their price movements. Northern Ireland's (NI) economy is distinct but should be linked to the rest of the UK by common policy shocks, and to Eire through a mutual border. The UK and Eire contain 
financial centres, through Dublin and London, which should be affected by common global financial forces. There are major commercial banks linking all three. All three experienced a house price bubble.

Harding \& Pagan (2002) lament a trend towards parametric approaches, away from graphical analyses of cycles, which they believe are more flexible and informative. Ranksbased approaches to multivariate testing, including Friedman's two way analysis of variance by ranks test, are proposed for considering cyclical similarity and symmetry. Using filtered data, deepness, which implies a bias in the shape of a cycle around the abscissa, is explored.

Second, it is averred that a housing cycle contains two component cycles; one in the business and one in the medium-term cycle range. Analysing integration at all three affords a view on DBT's claim that it is interaction between business and medium-term cycles that heralds a 'crisis.'

A third consideration is due to Richmond (2007) who argues that from 1996 to 2006 Dublin dislocates from the rest of Eire and tracks London. A fourth consideration is that, with a more fluid border resulting from the Good Friday Agreement and the rise of the Irish Celtic Tiger, there is greater integration or comovement in Ireland after 1996 than before. For the two, change should be evident in financial and business cycles, respectively.

The paper is constructed as follows. First, there is a discussion of theoretical channels linking markets. Next, the local context, British Isles is discussed. This is followed by a review of the methods applied and the data analysed. In the analysis, common cyclical distributions are assessed by applying the Friedman's two way analysis of variance by ranks and associated tests. 


\section{Market Integration}

DiPasquale \& Wheaton (1996) define a housing market as encompassing real estate sites that are influenced by the same economic conditions. They posit that price growth will be a function of the nature of the urban system and the industries it hosts. However, the urban border may not reflect the extent of the market. Meen (1999) provides a collection of explanations for the house price ripple effect [across UK regions], which describe how a shock to the high-priced London and the South East regions causes a 'deviation' from 'equilibrium' differentials with the rest of the regions, which is 'corrected' by others catching up. Meen's (1999) arbitrage forces that induce inter-regional price overspill include price expectations, labour migration and commuting. As such, a key agent of spatial arbitrage is labour.

\section{Finance and an International Housing Market}

As real income is the most significant single determinant of real house prices in the UK (Holly \& Jones, 1997), and that Meen (1999) characterises the British housing market as a series of structurally-diverse, interlinked, local markets, on the face of it, the assertion that there is an international housing market (Adams \& Füss, 2010; Helbling \& Terrones, 2003; Pomogajko \& Voigtländer, 2012) is at odds with above. However, as well as a durable consumer good, the house is an asset which can generate a financial return. Arbitrage between capital markets provides a channel of influence through which international price comovement could be facilitated. Holly et al. (2011) find that capital markets link cities' property prices across national borders. More generally, since the mid-1980s, reflecting rising trade and financial links, the world economy has become more integrated. A large share of the common component across national cycles is likely to reflect common monetary policy shocks or the tendency for greater financial globalisation (Hirata et al., 2012; Igan et al., 2011) particularly 
the leading role played by US monetary policy. Indeed, Meller \& Metiu (2017) chart a rise in credit cycle synchronisation, internationally.

Price rises are pro-cyclical, favouring highly-geared, expensive sites and regions (Smith \& Tesarek, 1991), such as in the south east of England or Dublin. Through enriched equity, rising price increases the bargaining power of owners seeking to trade. Moreover, banks, using lending metrics based on home equity and incomes, increase their lending, fortifying the price rise and acting as a financial accelerator (Stein, 1995; Aoki et al., 2004). Thus, compared with low, highly leveraged 'sites' could react more violently. A case recounted by Wood et al. (2016) features high dislocating from the low-priced sub-markets in Melbourne. Fernandez et al. (2016) argue that the London property market is a safe haven for a wealthy, international, elite, implying that it would have an international finance cycle, distinct from the rest of the UK. Richmond's (2007) London-Dublin thesis is consistent with this.

\section{The Context}

Kim and Renaud (2009) review the drivers of the global house price boom of the 2000s. One such, linked to historically low nominal and real interest rates, is the abundance of mortgage capital, packaged in innovative ways. Hay (2009) compares the UK and Irish experiences of house price inflation. He argues that for different institutional reasons, from the early 1990s, both pursued consumer-led growth strategies that fed on raised private debt levels. However, it was the incentives around allocating mortgage debt in both countries that inflated prices, propitiously. At the time of the financial crisis, two international banks, the Denmark based Danske Bank, and the British giant the Royal Bank of Scotland, owned subsidiaries on both sides of the Irish border. Coupled with Allied Irish Bank with the same characteristic, four banks bonded Northern Ireland to the fortunes of the rest of the Isles; to lax lending policies determined elsewhere that led to bank rescues; and to wider international credit conditions. 
There were institutional changes on the island of Ireland which would have altered growth and also the degree of market integration. Eire experienced a long economic upswing from 1996 but Kitchin et al. (2012) see two Celtic Tiger phases: the first phase attributed to multinational enterprises, EU/ Common Agricultural Policy, and a favourable tax climate for businesses is followed by the second phase of 2002-2006 which strongly linked to bank-led property finance and speculative construction. Moreover, the Good Friday Agreement (1998), which for all practical purposes expunged the land border between the north and south of Ireland, should precipitate greater integration at the business cycle level.

\section{Cyclical Characteristics}

De Groot and Franses (2008) illustrate how an economic series could be modelled by [a pair of] cycles. Detrending up to the medium-term range would expose the both shorter and longer cycle. Interference would obscure the impact of the higher frequency cycle, so that needs to be dissected. This is explored here. Aikman et al. (2015) (AHN) identify an 11-year periodicity in credit within a 130 year series of UK data. Defining this in the medium-term cycle range (8 to 20year), they also reveal a shorter cycle of $41 / 2$ years, which they place in their 2 to 8 -year, business cycle range. With an amplitude four to five times that of their business cycle, their credit cycle is reflected in the work of DBT who find a well-defined financial cycle drawn from the comovement of medium-term cycles in credit and property prices. For the purposes here, it is assumed that similarities identified in that range result from a common credit driver - revealing a financial channel between spatially distinct markets.

Levy \& Dezhbakhsh (2003) show UK GDP as having a single peak at around 6-8 years, which falls within AHN's business cycle range. Although Alexander \& Barrow (1994), Gray (2017) and the Royal Institution of Chartered Surveyors find cycles in UK property of around five to ten years, which traverses the bifurcation, Gray (2013) identifies a 6.4 and 5.3-year 
cycle in Eire's and Northern Ireland's property respectively. Complementing this, Agnello \& Schuknecht (2011) reveal up-and-down swings of over 14 years in UK and Eire house prices using a Hodrick-Prescott filter setting of 10,000, suggesting that housing cycles are found in the literature within the two ranges posited.

\section{Method}

A panel of time series $R_{i t}$ can be seen as comprising growth or trend elements $g_{i t}$ and cyclical elements $x_{i t}$. Thus, $R_{i t}=g_{i t}+x_{i t}$. Meller \& Metiu (2017) and AHN set the Christiano and Fitzgerald (2003) time-domain filter to extract periodicities in ranges 8 to 32 quarters (business cycle range) and 32 to 80 quarters (medium-term range). Combined, the full range of cycles considered is 2 years to 20 years (the aggregate range).

Time series analysis of comovement is beset by problems of noise, amplitude, delays, discontinuities, and temporal drift (Aghabozorgi et al., 2015). Here, a market is defined as having commonality in the cyclic components across sites of the market; specifically, that the cyclical elements are identically distributed, drawn from a common population. Identically distributed cyclic movement over time implies a 'similarity in shape in time.' Mink et al. (2011) propose two simple co-cyclical measures: synchronisation of cycles, where the periodicities of the series are considered; and similarity, where the 'shape' of the cyclical component is assessed. The former, which can also be seen in Harding \& Pagan (2002) and Meller \& Metiu (2017), transforms a cycle into values above 0 as +1 and those below as either 0 in the case of the former or -1 in the latter's paper. The approach taken here to revealing common/similar cycles among the sets of regional house price series entails variations on the Sign test, which, when assessing common medians, is not dissimilar in its binary nature. Using more information, the Wilcoxon sign test ranks the size of the deviations from a given median. To 
establish cyclical similarity among multiple series, a multiple Sign test, the Friedman test is employed.

The Friedman test does not require that the samples are of the same population; only that the matching is appropriate for the extraneous variables under consideration (Siegel \& Castellan, 1988). It is more robust to asynchronisation, cyclical asymmetry than conventional ANOVA tests and is more powerful with non-normal data as found in financial time series. The Friedman statistic $\left(F_{r}\right)$ (assuming no ties) is defined as: $\frac{12 \sum_{j=1}^{k} R_{j}^{2}}{\Lambda}-\frac{3 \Lambda}{T} \sim \chi_{k-1}^{2}(1)$ where $\Lambda=T k(k+1), t=$ time periods $t=1 . . T, k=$ number of market time series, and $R_{j}=$ sum of ranks in the jth column.

The cyclical element $x_{i t}$ will have both positive and negative values that vary over time so that $x_{i t}>x_{j t}$ is interspersed with $x_{i t+p}<x_{j t+p}$. Where they are similarly-shaped series, the number of occasions of the former is not dissimilar to the latter. When two or more weave around each other, the expected mean-rank of all should be about the same and the Friedman test will indicate they are drawn from a common population. This property can be considered using a clutch of sinusoidal series. As their values are symmetric around zero and they have the same shape, there will still be order-shuffling with different frequencies (assuming complete cycles), phase or amplitude.

Additionally, in a $k$-variate analysis, as outlined by Siegel \& Castellan (1988: 181), a pair of summed ranks can be compared, and discordant variable(s) can be identified. The test $\left|\overline{R_{1}}-\overline{R_{2}}\right| \geq z_{\alpha \# c} \sqrt{\frac{k(T+1)}{6}}$ (2) provides a test for differences in the mean-ranks of the first pair. With post hoc analysis involving multiple comparisons depending on $k$ and whether the test entails a control, $\alpha \# \mathrm{c}$ reflects adjustment to the critical value (Siegel \& Castellan, 1988, Table AII and AIII). 
The spread of mean-ranks can be thought of as a cross-sectional indicator of the variations in the cycles: higher means are indicative of a preponderance of high cyclic values. The Friedman test is used to distinguish different series' 'shapes;' specifically, differences in the distributions of values. Over a two period analysis, a fall in the range implies more similar shapes, akin to sigma convergence. For ease of interpretation, the mean-ranks are divided by $(k+1) \div 2$. As such, the spread is based on deviation from unity regardless of $k$ and convergence implies mean-ranks converging on unity. Critical values are adjusted accordingly.

A second set of tests can be conducted by adding a zero variable. There cannot be many cases that a variable comprising nothing can be useful. Siegel \& Castellan (1988: 181) show how the Friedman test can be used where a control variable is included in the variable set using (2). If that is a zero variable, de facto, deviation from its expected mean-rank provides a test for cyclical asymmetry.

Agnello \& Schuknecht (2011: 77) observe that long and severe booms tend to be followed by long and severe busts, implying symmetry. Different shapes above and below the abscissa are analysed using a variety of tests for deepness and steepness asymmetries (Mills, 2001). Deepness (troughs are deeper than peaks) and steepness (contractions are steeper and shorter-lived) imply that values are skewed. He finds cyclical patterns in macroeconomics time series are not asymmetry. Psaradakis \& Sola (2003) note that, unless they are prominent, finding asymmetries is unlikely. Cook (2006) finds the UK house prices exhibit 'highness' (the obverse of deepness) in that peaks are larger than troughs, but no steepness. NI exhibits neither. Holly \& Jones (1997) find that real house prices come back towards equilibrium much more quickly when they are above the cointegrating relationship than when they are below, implying a low value bias.

Asymmetry can emerge from combining two symmetric cycles. Assume $x_{i t}$ can be modelled by two sine waves of harmonic frequencies and of the same amplitude. Due to 
interaction (interference), it is possible for $x_{i t}$ to have twice the number of time periods with values below zero, so the series alternates between two small troughs and a small and a superpeak, the latter being the only one above zero. The interaction between business and mediumterm cycles that heralds a crisis could correspond with a series with a super-peak and asymmetry, where two cycles reinforce each other, resulting in a small number of large positive values. Where the Sign and Wilcoxon sign test provide conflicting inferences, it implies the assumption of symmetry is not fulfilled. The zero variable included in the Friedman test would distinguish the bias in the number of cases. This is captured by significant difference between the control, the zero variable, and at least one market's mean-rank. If there is a preponderance of negative value across the data sets, the mean-rank of the zero variable will be above unity. If they have a zero mean, the positive cyclic values must be relatively large - the sample has a positive skew.

The Page test for ordered alternatives (Siegel \& Castellan, 1988: 184) is an extension of the Friedman test. Friedman test considers only spread. The Page test assesses the alternative hypothesis that the mean-ranks reflect some structural order. The Page statistic $\left(P_{r}\right)$ is given as: $\frac{12 L-3 \Lambda(k+1)}{k\left(k^{2}-1\right)} \sqrt{\frac{(k-1)}{T}} \sim Z_{\alpha}(0,1)(3)$, where $L=R_{1}+2 R_{2}+3 R_{3}+\ldots+k R_{k}$.

\section{Data}

Second-hand house prices data for Eire and Dublin are taken from Eire's Department of Environment, Heritage and Local Government. The quarterly data covers the period 1978Q1 to 2015Q2. The London, UK and Northern Ireland data are drawn from the Nationwide Building Society's web site. This data is for Modern housing. Average house prices are mix adjusted and based on loan approval data, supplied by the mortgage lending agencies. Second- 
hand (Eire/Dublin) and Modern ${ }^{1}$ (UK/NI/London) dwellings are chosen specifically as their owner (-occupier), because of their equity in the property, is likely to subject to the financial effects posited by Stein (1995) and Aoki et al. (2004) when prices rise.

The house prices are deflated by inflation indices. For the UK and Northern Ireland, Retail Price Index is taken from the Office for National Statistics. Eire's Consumer Prices Index values are taken from the Central Statistical Office. The house price data is analysed in natural logarithm form in real terms and adjusted using exchange rate data taken from the CSO. UK data includes Northern Ireland.

Over the full series, Table 1 indicates that UK house prices grew at an annual rate of $2.45 \%$. The rate was far more rapid in the second (3.55\%) than in the first era (1.27\%) of 19781995. This is the case for all three regional and the two city markets. The volatility is assessed by variance. The volatility across Eire's 2-year to 20-year cycle range (84.5) can be broken down in to the financial (61.0) and the business cycle (19.1) components. The residual can be attributed to the covariance between the latter two. Volatility increased on the island of Ireland across the two eras. In the case of NI, this is mostly due to factors captured by the financial cycle, whereas in Eire, the split is far more even. Although small, the two cases of negative covariance occur in the first era, supporting the claim that there was the business-financial cycle off-setting. Leamer (2007) argues that housing and business cycles are the same. This revolves around dwelling construction driving income. It is notable that speculative construction go hand-in-hand with finance in Ireland (Kitchin et al., 2012), an issue that is not that observable in the UK. Despite more rapid growth, the UK is unusual in having a less volatile, declining business cycle but stable in aggregate. London has by far the greatest change in growth, yet the cycle volatility declines.

\footnotetext{
${ }^{1}$ Nationwide had two categories of second-hand dwelling - Modern and Older. The former, as a proxy for both, is no longer collected.
} 
Following Harding \& Pagan (2002), there is a graphical analysis of cycles. For illustrative purposes comparing the aggregate with the constituent business and financial series, Eire's market price-cyclic characteristics are displayed in Figure 1. The 20-year (aggregate cycle) has more rapid movement so that peak-to-trough is generally larger that the business cycle. However, this is not always the case. Indeed, peaks are not necessarily associated with reinforcing financial-business cycle interactions. There was not much difference in amplitude between all three series during the period from 1978 to 1987 . As the amplitude of the 2 to 20year 'aggregate' series is the sum of the other two, this suggests that the financial and business cycles off-set as much as they reinforced each other. Kitchin et al.'s (2012) two eras are evident. The upswing from 1996 to 1999 is a complete business cycle whereas for the financial cycle the series has a deviation from an upward trend at that time. It is as if there is one Celtic Tiger era in the medium-term range and two in the shorter business cycle range.

The aggregate 20-year series for the UK, displayed in Figure 1, highlights a price cycle closely linked to a stable financial cycle. Taking Agnello \& Schuknecht's (2011) definition of a boom or bust as a deviation from the price trend at over $10 \%(0.1$ on the cycle scale), the UK has a large event on a regular basis. It appears to be subject to asymmetry.

Despite being part of the UK, constitutionally, Northern Ireland's profile is very different. The peak in 2007 illustrates a bubble with an unusually high price, a rapid rise, and fall over a long period. Moreover, the gap between the financial and the aggregate full range is very large at this single event, reflecting the reinforcement of the business cycle. There is a descending financial cycle. 
Figure 1 Three sets of 3 Price Cycles

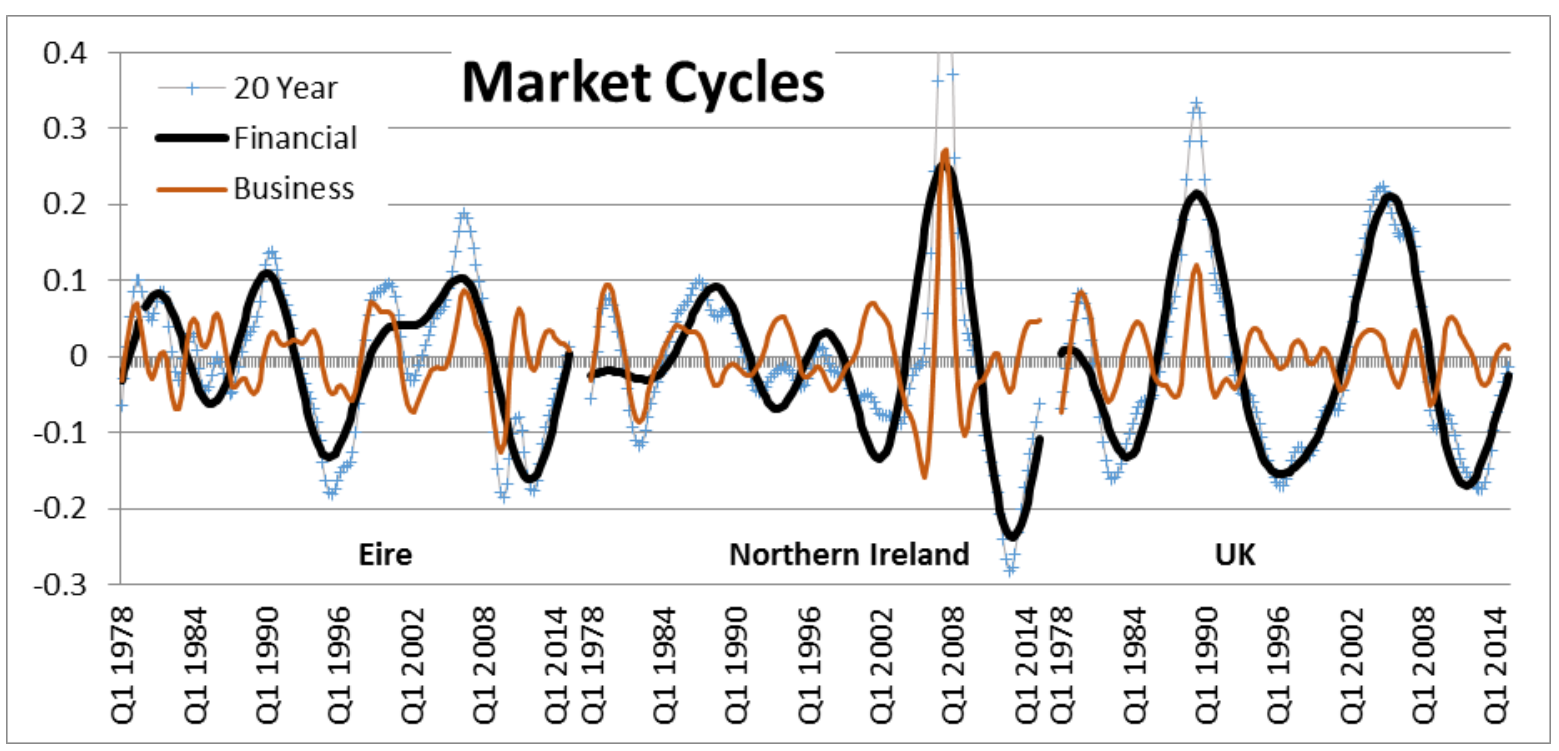

Table 1 Variance, Growth and Autocorrelation Over Eras

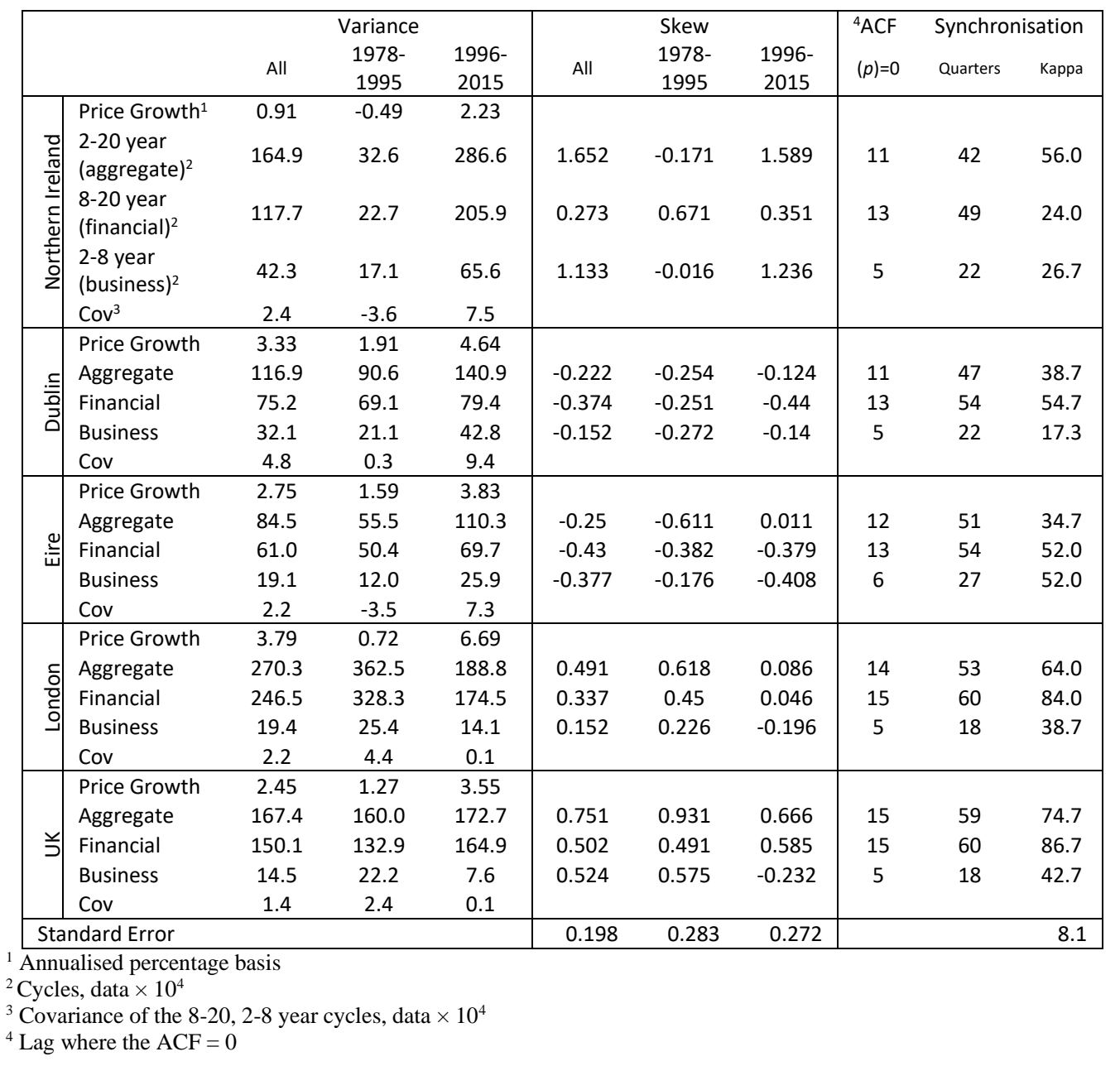


If $x_{i t}$ is a sinusoidal series, its autocorrelations will follow a cosine function. As such, $r\left(x_{i t}, x_{i t-p}\right)=0$ at one quarter of a cycle. So where $\operatorname{ACF}(p)>0$ but $\operatorname{ACF}(p+1)<0, p$ is an indicator of $1 / 4$ of the periodicity. From Table 1 , this indicates periodicities around 5 and 13 years for NI's business and financial cycles, with 'average' periodicity of 11 years across the aggregate series.

Cohen's Kappa ( $\kappa)$ assesses the proportion of agreement between $\left(x_{i t}\right)$ and $\left(x_{j t}\right)$ over and above chance agreement. It is interpreted like a correlation coefficient. The filtered variable $x_{i t}$ is indexed where $I\left(x_{i t}\right)=1$ if $x_{i t}>0$ and -1 otherwise, so that $I\left(x_{i t}\right)$ is binary. Non-cyclical house price series could be expected to cross the abscissa at random intervals. By benchmarking each series against equivalently treated sinusoidal binary variable with various periodicities, there is a joint consideration of cyclicality and the periodicity (Gray, 2018a). UK's Kappa of 0.75 is associated with a cycle of 59 quarters or 15 years, which is in keeping with the long phases of Meen (2011) the credit cycle of AHN, and Agnello \& Schuknecht's estimates. Eire/Dublin medium-term range cycle is also in line with Agnello \& Schuknecht. The business cycle periodicities are in keeping with findings of authors cited earlier.

Having shown graphically how distinct the three are, to assess the homogeneity of distributions, the Friedman test is applied to the three regional markets across both cycles and in aggregate. The interpretation of the Friedman statistic $\left(\chi^{2}=12.65[0.002]\right)$ is that, across the aggregate regional cycles, the markets appear to be distinctive, or prices are drawn from different populations for the whole period and the sub-periods: there is no unified market.

Using the zero variable as a control, the UK series is found to be distributed asymmetrically $(1.092-0.876>0.14)$, the low rank sum suggesting that it has a bias of periods below zero. The interpretation here is that this is the product of a relatively large number of negative cases, which is consistent with a positive skew in Table one. Moreover, Cook (2006) concludes that UK prices exhibit tall peaks. Indeed, NI also has this characteristic. However, 
again consistent with Cook in the first era, NI's prices do not appear biased. Interestingly, the zero coefficient being higher than the others in the second era, indicates that the set is skewed positively, supported in the cases of the UK and NI directly.

Having concluded that there is no integrated housing market when using the aggregate cycles among the three, the constituent elements are reviewed. Results in Table 2 (panel A) indicate that the thesis of integration at the business cycle level (Pomogajko \& Voigtländer, 2012) is not refuted. The financial cycles for the three regions are also found to be very similar (2.253 [0.324]). Indeed, this is the case across both eras.

Table 2 Tests for Similar Cycles

\begin{tabular}{|c|c|c|c|c|c|c|c|c|c|c|c|c|c|c|c|c|c|c|}
\hline \multirow{3}{*}{$\begin{array}{l}\text { Regional } \\
\text { Cycle }\end{array}$} & \multicolumn{6}{|c|}{ Table 2 Panel A } & \multicolumn{6}{|c|}{ Table 2 Panel B } & \multicolumn{6}{|c|}{ Table 2 Panel C } \\
\hline & \multicolumn{3}{|c|}{$\begin{array}{l}\text { Separate, Without Zero } \\
\text { Variable }\end{array}$} & \multicolumn{3}{|c|}{ Separate, With Zero Variable } & \multicolumn{3}{|c|}{$\begin{array}{l}\text { Combined, Without Zero } \\
\text { Variable }\end{array}$} & \multicolumn{3}{|c|}{$\begin{array}{c}\text { Combined, With Zero } \\
\text { Variable }\end{array}$} & \multicolumn{2}{|c|}{ All } & \multicolumn{2}{|c|}{ 1978-1995 } & \multicolumn{2}{|c|}{ 1996-2015 } \\
\hline & All & $\begin{array}{c}1978- \\
1995 \\
\end{array}$ & $\begin{array}{r}1996- \\
2015\end{array}$ & All & $\begin{array}{l}1978- \\
1995\end{array}$ & $\begin{array}{l}1996- \\
2015\end{array}$ & All & $\begin{array}{c}1978- \\
1995 \\
\end{array}$ & $\begin{array}{l}1996- \\
2015 \\
\end{array}$ & All & $\begin{array}{c}\text { vallate- } \\
1978- \\
1995 \\
\end{array}$ & $\begin{array}{c}1996- \\
2015 \\
\end{array}$ & $\begin{array}{c}\text { Wilcox- } \\
\text { on }^{7}\end{array}$ & $\operatorname{Sign}^{7}$ & $\begin{array}{l}\text { Wilcox- } \\
\text { on }\end{array}$ & Sign & $\begin{array}{l}\text { Wilcox- } \\
\text { on }\end{array}$ & Sign \\
\hline Eire 2-20y & $1.11^{1}$ & $1.085^{1}$ & $1.135^{1}$ & 1.092 & 1.084 & 1.104 & & & & & & & 0.905 & 0.806 & 0.162 & 0.556 & 0.353 & 0.91 \\
\hline NI 2-20y & 0.985 & 1.05 & $0.925^{1}$ & $0.936^{3}$ & 1.032 & $0.848^{3}$ & & & & & & & $0.018^{*}$ & $0.003^{*}$ & 0.346 & 0.906 & $0.001^{*}$ & $0.000^{*}$ \\
\hline UK 2-20y & $0.905^{1}$ & $0.87^{1}$ & 0.94 & $0.876^{3}$ & 0.868 & $0.888^{3}$ & & & & & & & \multirow[t]{4}{*}{0.227} & \multirow[t]{4}{*}{$0.004^{*}$} & \multirow[t]{4}{*}{0.703} & \multirow[t]{4}{*}{0.289} & \multirow[t]{4}{*}{0.299} & \multirow[t]{4}{*}{$0.005^{*}$} \\
\hline \multirow{3}{*}{$\begin{array}{l}\text { Zero } \\
\chi^{2} \\
p \text {-value }\end{array}$} & & & & 1.092 & 1.016 & 1.164 & & & & & & & & & & & & \\
\hline & $12.65^{*}$ & $7.69^{*}$ & $8.54^{*}$ & $20.57^{*}$ & 7.05 & $21.6^{*}$ & & & & & & & & & & & & \\
\hline & 0.002 & 0.021 & 0.014 & 0.000 & 0.07 & 0.000 & & & & & & & & & & & & \\
\hline Eire 8-20y & 1.05 & 1 & 1.095 & 1.056 & 1.016 & 1.092 & 1.020 & 1.000 & 1.037 & 1.028 & 1.010 & 1.043 & 0.886 & 0.369 & 0.321 & 0.556 & 0.285 & 0.571 \\
\hline NI 8-20y & 0.975 & 0.95 & 0.995 & 0.94 & 0.9 & 0.976 & 0.937 & 0.917 & 0.957 & 0.920 & 0.890 & 0.948 & 0.149 & $0.018^{*}$ & 0.602 & $0.013^{*}$ & 0.294 & 0.428 \\
\hline UK 8-20y & 0.975 & 1.05 & 0.91 & 0.944 & 1.024 & 0.872 & \multirow[t]{4}{*}{$0.897^{1}$} & \multirow[t]{4}{*}{0.949} & \multirow[t]{4}{*}{0.849} & \multirow[t]{3}{*}{0.888} & \multirow[t]{4}{*}{0.945} & \multirow[t]{4}{*}{0.833} & \multirow[t]{4}{*}{0.375} & $0.027^{*}$ & 0.955 & 0.556 & 0.225 & $0.017^{*}$ \\
\hline \multicolumn{4}{|l|}{ Zero } & 1.06 & 1.06 & 1.06 & & & & & & & & & & & & \\
\hline$\chi^{2}$ & 2.253 & 1.361 & 5.41 & 7.76 & 3.917 & $8.6^{*}$ & & & & & & & & & & & & \\
\hline$p$-value & 0.324 & 0.506 & 0.067 & 0.051 & 0.271 & 0.035 & & & & & & & & & & & & \\
\hline Eire 2-8y & 1.005 & 0.98 & 1.03 & 1.028 & 1.012 & 1.04 & 1.054 & 1.043 & 1.063 & 1.060 & 1.055 & 1.065 & 0.461 & 0.221 & 0.732 & 0.289 & 0.634 & 0.571 \\
\hline NI 2-8y & 0.995 & 1.07 & 0.93 & 0.98 & 1.06 & 0.904 & $1.069^{1}$ & 1.089 & 1.051 & 1.048 & 1.080 & 1.020 & 0.914 & 0.288 & 0.211 & 0.906 & 0.328 & 0.089 \\
\hline UK 2-8y & 0.995 & 0.95 & 1.04 & 0.996 & 0.956 & 1.036 & 1.026 & 1.003 & 1.043 & 1.023 & 1.000 & 1.043 & 0.752 & 1.000 & 0.897 & 0.906 & 0.998 & 0.91 \\
\hline Zero & & & & 0.996 & 0.972 & 1.02 & & & & 1.038 & 1.020 & 1.053 & & & & & & \\
\hline$\chi^{2}$ & 0.04 & 2.194 & 2.333 & 0.664 & 1.783 & 3.769 & $12.1^{*}$ & 4.825 & 9.355 & $14.25^{*}$ & 6.28 & 10.96 & & & & & & \\
\hline $\begin{array}{l}\text { n-value } \\
p\end{array}$ & 0.98 & 0.334 & 0.311 & 0.822 & 0.619 & 0.287 & 0.033 & 0.438 & 0.096 & 0.027 & 0.393 & 0.09 & & & & & & \\
\hline Ranks $^{2}$ & 0.138 & 0.200 & 0.192 & & & & 0.163 & 0.235 & 0.226 & & & & & & & & & \\
\hline Control $^{4}$ & & & & 0.140 & 0.202 & 0.194 & & & & 0.160 & 0.231 & 0.222 & & & & & & \\
\hline Page Varianc & & & & & & & 2.911* & & & $3.064^{*}$ & & & & & & & & \\
\hline$p$-value & & & & & & & 0.002 & & & 0.001 & & & & & & & & \\
\hline Page Skew ${ }^{6}$ & & & & & & & -0.266 & & & 0.246 & & & & & & & & \\
\hline$p$-value & & & & & & & 0.395 & & & 0.403 & & & & & & & & \\
\hline $\begin{array}{l}{ }^{1} \text { Significantly } \\
{ }^{2} \text { Critical Valu } \\
{ }^{3} \text { Significantly }\end{array}$ & $\begin{array}{l}\text { Different } \\
\text { e Differen } \\
\text { Different }\end{array}$ & $\begin{array}{l}\text { Values } \\
\text { ce in Mean } \\
\text { Values fror }\end{array}$ & $\begin{array}{l}\text { Ranks at } \\
\text { Zero co }\end{array}$ & $5 \%$ lev & & & $\begin{array}{l}{ }^{4} \text { Critical } \\
\text { 5Page Te } \\
\text { 6Page Te }\end{array}$ & $\begin{array}{l}\text { alue Diffe } \\
\text { at based } \\
\text { t based o }\end{array}$ & $\begin{array}{l}\text { varianc } \\
\text { skew o }\end{array}$ & $\begin{array}{l}\text { n Zero Con } \\
\text { order in T. } \\
\text { fer in Table }\end{array}$ & $\begin{array}{l}\text { trol at t } \\
\text { ble } 1\end{array}$ & & $\begin{array}{l}{ }^{7} \text { Tests of } \\
{ }^{*} \text { Sig at } 5\end{array}$ & $\begin{array}{l}\text { ulll of ze } \\
\text { blevel }\end{array}$ & & values & & \\
\hline
\end{tabular}

Adding the zero variable reveals weak evidence of an asymmetry in the financial series across the whole period, with all having a bias of values below zero. In the second era, the spread is now significant. Although the mean is not different from zero for all cycles (not reported), both the Sign and the Wilcoxon tests for NI and at the 20-year and financial cycle in Table 2 (panel C) suggest the medians are not zero. A complicating factor is the cycle periodicity relative to the length of the series. A high number of low values could reflect capturing more troughs than peaks. Eyeballing Figure 1, confirms that large spike skews the mean away from the median, which is picked up by both rank tests. In the case of the UK, the 
two Sign test results, that indicate a positive skew, do not appear to be related to the starting point in the cycle. NI has a single very large spike distorting what is a downward trend. The Friedman test confirms the bivariate results with the aggregate cycle but not others. The bias found in the financial cycles is not supported on a multivariate basis.

Having concluded that business and financial cycles are drawn from common populations separately, there is consideration of whether this is the case across all 6 series. It is inferred from the results in Table 2 (panel B) that the business and financial cycles are not distributed similarly for the whole period $\left(\chi^{2}=12.1[0.033]\right)$ but are for the sub-periods.

The schism over similarity between the full and sub-period results is considered by using the orders of variance, [kurtosis] and skew. The one-tailed Page test of the null of no corresponding order with variance is rejected. The insertion of the zero variable, fourth in mean-rank order, into the set does not alter that inference $(z=3.064[0.001]$ in Table 2 (panel B). Overall, volatility is associated with lower mean-ranks: longer cycles have greater volatility. This is not the case for skew or kurtosis (not reported).

Over an extended period and using similar data, Gregoriou et al. (2014) find the house price-earnings ratio is not mean-reverting: it drifts upwards. Buyers require larger loans per unit income. This growing spread associated with the liberalisation of the second era is more likely to affect Ireland, which deregulated later than the UK. In Figure 1 there is escalating volatility and a downward trend in the financial cycles in Ireland which corresponds with a broadening range of Friedman coefficients across the two eras reported in Table 2 (panel B). The UK and Ireland may face increasingly different skews; the former having tall peaks, and the latter, deep troughs. The financial cycle becoming more volatile could explain why the schism between the financial and business cycle becomes significant over the entire period. 


\section{City Dislocation}

Although Richmond's (2007) dislocation thesis is about altering trend, evidence presented in Table 3 appears to confirm this change in the alignment using cycles. The London-Dublin relationship for the post-1995 era is associated with a common distribution for the 20 -year cycles $(1.103[0.576])$, whereas in the earlier period there is a distinction (13.361 [0.001]). Indeed, this reflects the shift in the constituent business and financial cycles where the values converge on unity. Moreover, aligned with Cook's (2006) finding for London, these results are consistent with cyclical symmetry, but only for the second era.

Table 3 City Cycles Combined

\begin{tabular}{|c|c|c|c|c|c|c|}
\hline \multirow{2}{*}{$\begin{array}{l}\text { Regional } \\
\text { Cycle }\end{array}$} & \multicolumn{3}{|c|}{ Without Zero Variable } & \multicolumn{3}{|c|}{ With Zero Variable } \\
\hline & All & $\begin{array}{c}1978- \\
1995\end{array}$ & $\begin{array}{l}1996- \\
2015\end{array}$ & All & $\begin{array}{c}1978- \\
1995\end{array}$ & $\begin{array}{l}1996- \\
2015\end{array}$ \\
\hline DUB 2-20year & 1.107 & 1.17 & 1.05 & 1.085 & 1.13 & 1.045 \\
\hline LON 2-20 year & 0.893 & 0.83 & 0.95 & 0.9 & $0.835^{1}$ & 0.96 \\
\hline Zero & & & & 1.015 & $1.035^{1}$ & 0.995 \\
\hline$\chi^{2}$ & $15.36^{*}$ & $18.00^{*}$ & 1.846 & $10.613^{*}$ & $13.361^{*}$ & 1.103 \\
\hline$p$-value & 0.000 & 0.000 & 0.174 & 0.005 & 0.001 & 0.576 \\
\hline Control & & & & 0.128 & 0.184 & 0.177 \\
\hline DUB 8-20year & 1.02 & 1.02 & 1.02 & 1.03 & 1.04 & 1.02 \\
\hline DUB 2-8 year & $1.06^{1}$ & 1.06 & 1.05 & 1.05 & 1.07 & 1.03 \\
\hline LON 8-20 year & $0.88^{1}$ & 0.86 & 0.91 & 0.88 & 0.85 & 0.91 \\
\hline LON 2-8 year & $1.04^{1}$ & 1.06 & 1.02 & 1.04 & 1.06 & 1.02 \\
\hline Zero & & & & 0.99 & 0.98 & 1.01 \\
\hline$\chi^{2}$ & $10.26^{*}$ & 7.78 & 3.19 & $10.06 *$ & 8.52 & 2.656 \\
\hline$p$-value & 0.017 & 0.051 & 0.364 & 0.039 & 0.074 & 0.617 \\
\hline Ranks & 0.149 & 0.215 & 0.207 & & & \\
\hline Control & & & & 0.149 & 0.214 & 0.206 \\
\hline Page Variance & $2.758^{*}$ & & & $2.278^{*}$ & & \\
\hline$p$-value & 0.003 & & & 0.011 & & \\
\hline Page Skew & $2.333^{*}$ & & & $2.058^{*}$ & & \\
\hline$p$-value & 0.01 & & & 0.02 & & \\
\hline
\end{tabular}

\section{Discussion}

When separate, it is shown that the cyclic series of the three 'regions' and two 'cities' have periodicities corresponding with business and financial cycles. In Figure 1 (UK in 1989 and NI in 2007) there are large deviations between the financial and aggregate cycles, where the financial and business cycles reinforce each other. The thesis that there is an international 
housing market in line with Adams \& Füss (2010) and Pomogajko \& Voigtländer (2012) is supported using both the business and financial cycles. Taking the aggregate cycle as a product of the unobserved interaction of business and financial cycles, this is undermined, leaving the group more as structurally-diverse, interlinked, regional markets. It is concluded that DBT's claim of interaction, rather than the cycle range, is where the distinctions lie. It is local interaction that determines the shape of a housing cycle.

In the run up to the financial crisis a review of housing by the OECD in 2005 highlighted a uniformity in the literature that the pre-1995 era was different to the 1995-2005 period. Price cycle duration was longer and the upswings were more generalised across OECD countries than in the past. In this context, Richmond's (2007) dislocation thesis provides a case where finance generated alignment. With a convergence of values, London-Dublin market integration is found in cycles in the post-1995 era.

Another general finding is of asymmetry in financial cycles: in the cases of NI and the UK, having tall peaks. The asymmetry, in the second era, is not evident in London's or Dublin's, the most leveraged markets. Rather than highly-leveraged housing markets responding earlier and more vigorously than others (Smith \& Tesarek, 1991), it could be that the parts of the country outside of the Capital are inefficient in absorbing house price information (Tsai, 2015) linked to the financial cycle and 'catch up' in a manner that appears as a 'ripple.' This could be seen most acutely in Northern Ireland after the Good Friday Agreement. If so, mortgage lenders act locally; accelerating rather than stimulating growth, suggesting an integrated banking sector across the two parts of Ireland would not induce cyclical similarity, automatically. The asymmetry could also be related to a reactive policy response, which is also informationally inefficient. Policy makers are able to ameliorate a national downturn once they know it is occurring in London. 


\section{Conclusion}

Using a similarity of cycles criterion, the paper considers whether there is evidence for an international market in housing using a case study of three closely linked markets in the British Isles. It is proposed that Friedman's two way analysis of variance by ranks and associated tests can be employed to reveal similarity across price cycles in a panel for this purpose.

A number of novel features are found in this paper. First, rather than using a single, aggregate series capturing 2 to 20 -year cycles, a bifurcation into business and financial cycles provides more insight into market integration across the UK, Eire and Northern Ireland. Although there are notable similarities in the business cycles, it is inferred that it is financial-business interaction that makes them distinctive.

First, the results do not provide evidence for change in the nature of integration due to the Good Friday Agreement in Ireland to be inferred. This could be a function of the relative importance of the medium-term cycles obscuring business cycle activity and accord with DBT in the former's association with periodic crises in housing. For Northern Ireland, rather than integration, perhaps there is a realignment of prices, catching-up after the Good Friday Agreement in 1998. Indeed, this ties in with the second conclusion that, consistent with Pomogajko \& Voigtländer (2012), there is evidence for an integrated international housing market with business cycles. However, it is not found on aggregate or in financial cycles in the second era. The latter finding is in the context of an integrated banking sector. Using a broader range of cycles, where local cycle interaction is probably idiosyncratic, not only will regional integration be less likely to exist, but also policy prescriptions need to reflect local interaction.

Third, the use of a zero variable reveals that cycle asymmetry, probably highness, where the peaks are greater than the troughs, is found in UK and Northern Irish house prices. Fourth, evidence is found that supports the thesis that financial liberalisation generates integration among international cities, but this can dislocate them from the rest of their countries: a 
worrying feature that has provoked international restrictions on capital movements in New Zealand, amongst others.

Lastly, the UK seems to have a relatedly important financial cycle that heralds regular, large events. Overlooking the slower burner of the medium-term cycle and policy focusing on shorter-term problems linked to the business cycle could result in interest rate policy being counter-productive (Borio, 2014). Recently, for counter-financial-cyclic policy measures, the Bank of England and the Central Bank of Ireland ${ }^{2}$ began regulating lending metrics. The latter Bank imposes less onerous credit constraints on first time buyers compared with those that own. The repeat buyers feature strongly in the financial accelerator process, so restricting their access to mortgage finance is a logical step. That said, Gregoriou et al. (2014) see the long term rise in house prices in the UK relative to income. Bank and household balance sheets hold more debt as a result, making the financial and real economies more volatile and less resilient to adverse shocks.

Driving that lending metric down so that financial resilience is improved and better access to 'affordable' loans should be the policy aim. Inflated prices, as supported by high loan-to-income lending, are socially divisive, transferring wealth from the younger to the older generation. The Bank of England does not make the same buyer distinction. It should.

\section{References}

Adams, Z. \& Füss, R. (2010) Macroeconomic determinants of international housing markets, Journal of Housing Economics, 19(1), 38-50.

Aghabozorgi, S., Shirkhorshidi, A., \& Wah T. (2015) Time-Series Clustering - A Decade Review, Information Systems, 53, 16-38.

\footnotetext{
$2_{\text {https://www.centralbank.ie/financial-system/financial-stability/macro-prudential-policy/mortgage-measures accessed 6/2/18 }}$ https://www.bankofengland.co.uk/-/media/boe/files/statement/2015/the-financial-policy-committees-powers-over-housingtools.pdf?la=en\&hash $=824555 \mathrm{~A} 3 \mathrm{E} 0 \mathrm{E} 43904679511189 \mathrm{~F} 70706 \mathrm{FC} 5 \mathrm{EE} 5 \mathrm{EA} 2$ accessed $1 / 2 / 18$
} 
Agnello, L. \& Schuknecht, L. (2011) Booms and Busts in Housing Markets: Determinants and Implications, Journal of Housing Economics, 20(4), 171-190.

Aikman, D., Haldane, A. \& Nelson, B. (2015) Curbing the Credit Cycle, The Economic Journal, 125, (June), 1072-1109.

Alexander, C. \& Barrow, M. (1994) Seasonality and Cointegration of Regional House Prices in the UK, Urban Studies, 31, 1667-1689.

Aoki, K., Proudmand, J. \& Vlieghe, G. (2004) House Prices, Consumption and Monetary Policy: a Financial Accelerator Approach, Journal of Financial Intermediation, 13, 414-435.

Borio, C. (2014) The Financial Cycle and Macroeconomics: What have we learnt? Journal of Banking \& Finance, 45, 182-198.

Christiano, L. \& Fitzgerald, T. (2003) The Band Pass Filter, International Economic Review, $44(2), 435-465$.

Clark, S. \& Coggin, D. (2009) Trends, Cycles and Convergence in U.S. Regional House Prices, Journal of Real Estate Finance \& Economics, 39(3), 264-283.

Cook, S. (2006) A Disaggregated Analysis of Asymmetrical Behaviour in the UK Housing Market, Urban Studies, 43, 2067-2074.

Crone, T. (2005) An Alternative Definition of Economic Regions in the United States Based on Similarities in State Business Cycles, The Review of Economics and Statistics, 87(4), 617626.

De Goei, B., Burger, M., Van Oort, F. \& Kitson M. (2010) Functional Polycentrism and Urban Network Development in the Greater South East, United Kingdom: Evidence from Commuting Patterns, 1981-2001, Regional Studies, 44(9), 1149-1170.

De Groot, B. \& Franses, P. (2008) Stability Though Cycles, Technological Forecasting and Social Change, 75, 301-311. 
De Haan, J., Inklaar, R. \& Jong-A-Pin, R. (2007) Will Business Cycles in the Euro Area Converge? A Critical Survey of Empirical Research, Journal of Economic Surveys, 22(2), 234273.

DiPasquale, D. \& Wheaton, W. (1996) Urban Economics and Real Estate Markets, Englewood Cliffs, NJ, USA: Prentice Hall.

Drehmann, M., Borio, C. \& Tstasaronis, K. (2012) Characterising the Financial Cycle: don't lose sight of the Medium Term!, BIS Working Papers, No. 380, Bank for International Settlements, June.

Fernandez, R., Hofman, A. \& Albers, M. (2016) London and New York as a Safe Deposit Box for the Transnational Wealth Elite, Environment and Planning A, 48(12), 2443-2461.

Gray, D. (2013) House Price Diffusion: An Application of Spectral Analysis to the Prices of Irish Second-Hand Dwellings, Housing Studies, 28(7), 869-890.

Gray, D. (2017) Cycles in the UK Housing Economy: Price and its Relationship with Lenders, Buyers, Consumption and Construction, Springer: Cham, Switzerland.

Gray, D. (2018a) An Application of Two Non-Parametric Techniques to the Prices of British Dwellings: An Examination of Cyclicality, Urban Studies, 55(10), 2286-2299.

Gray, D. (2018b) Convergence and Divergence in British Housing Space, Regional Studies, 52(7), 901-910.

Gregoriou, A., Kontonikas, A. \& Montagnoli, A. (2014) Aggregate and Regional House Price to Earnings Ratio Dynamics in the UK, Urban Studies, 51, 2916-2927.

Harding, D. \& Pagan, A. (2002) Dissecting the cycle: a methodological investigation, Journal of Monetary Economics, 49, 365-81.

Hay, C. (2009) Good Inflation, Bad Inflation: The Housing Boom, Economic Growth and the Disaggregation of Inflationary Preferences in the UK and Ireland, The British Journal of Politics and International Relations, 11(3), 461-478. 
Helbling, T. \& Terrones, M. (2003) When Bubbles Burst - Chapter II, World Economic Outlook, IMF: Washington, D.C, USA, April.

Hirata, H., Kose M., Otrok, C., Terrones, M. (2013) Global house price fluctuations: Synchronization and determinants, Working Paper No. 18362, NBER.

Holly, S. \& Jones, N. (1997) House prices since the 1940s: cointegration, demography and asymmetries, Economic Modelling, 14, 549-565.

Holly, S., Pesaran, H. \& Yamagata, T. (2011) The Spatio-Temporal Diffusion of House Prices in the UK, Journal of Urban Economics, 69(1), 2-23.

Igan, D., Kabundi, A., Nadal De Simone, F., Pinheiro, M. \& Tamirisa, N. (2011) Housing, credit, and real activity cycles: Characteristics and comovement, Journal of Housing Economics, 20(3), 210-231.

Kim, K. \& Renaud, B. (2009) The Global House Price Boom and its Unwinding: An Analysis and a Commentary, Housing Studies, 24(1), 7-25.

Kitchin, R., O’Callaghan, C., Boyle, M., Gleeson, J. \& Keaveney, K. (2012) Placing Neoliberalism: The Rise and Fall of Ireland's Celtic Tiger, Environment and Planning A, 44(6), $1302-1326$.

Leamer, E. (2007) Housing is the Business Cycle, Working Paper 13428, NBER.

Levy, D. \& Dezhbakhshb, H. (2003) International Evidence on Output Fluctuation and Shock Persistence, Journal of Monetary Economics, 50, 1499-1530.

Meen, G. (1999) Regional House Prices and the Ripple Effect: A New Interpretation. Housing Studies, 14(6), 733-753.

Meen, G. (2011) The Economic Consequences of Mortgage Debt, Journal of Housing and the Built Environment, 26(3), 263-276.

Meller, B. \& Metiu, N. (2017) The synchronization of credit cycles, Journal of Banking and Finance, 82, 98-111. 
Mills, T. (2001) Business cycle asymmetry and duration dependence: an international perspective, Journal of Applied Statistics, 28(6), 713-725.

Mink, M., Jacobs, J. \& de Haan, J. (2012) Measuring coherence of output gaps with an application to the Euro area, Oxford Economic Papers, 64(2), 217-236.

Montagnoli, A. \& Nagayasu, J. (2015) UK House Price Convergence Clubs and Spillovers, Journal of Housing Economics, 30, 50-58.

OECD (2005) Recent House Price Developments: the Role of Fundamentals. Ch 3. Economic Outlook 78, 123-154.

Pomogajko, K. \& Voigtländer, M. (2012) Co-movement of House Price Cycles - a Factor Analysis, International Journal of Housing Markets \& Analysis, 5(4), 414-427.

Psaradakis, Z. \& Sola, M. (2003) On detrending and cyclical asymmetry, Journal of Applied Econometrics, 18(3), 271-289.

Richmond, P. (2007) A roof over your head; house price peaks in the UK and Ireland, Physica A: Statistical Mechanics and its Applications, 375(1), 281-287.

Royal Institution of Chartered Surveyors (1999) UK Property Cycle - A History from 1921 to 1997, RICS Books: London.

Siegal, S. \& Castellan, N. (1988) Nonparametric Statistics, New York: McGraw-Hill.

Smith, B. \& Tesarek, W. (1991) House Prices and Regional Real Estate Cycles: Market Adjustments in Houston, Real Estate Economics, 19(3), 396-416.

Stein, J. (1995) Prices and Trading Volume in the Housing Market: a Model with Downpayment Effects, The Quarterly Journal of Economics, 110, 379-405.

Tsai, I-C. (2015) Spillover Effect between the Regional and the National Housing Markets in the UK, Regional Studies, 49(12), 1957-1976.

Wood, G., Sommervoll, D. \& De Silva, A. (2016) Do Urban House Prices Converge? Urban Policy and Research, 34(2), 102-115. 